\title{
Design and Status of the XFEL RF System
}

\author{
Stefan Choroba, DESY
}

for the XFEL Work Package High Power RF 


\section{Outline}

- Introduction

- RF System Requirements

- RF System Main Components

- RF Power Source

- Modulator

- RF Waveguide Distribution

- Interlock

- Other Components

- LLRF

- Summary 


\section{Introduction}

-Early 1990s start of the TESLA Collaboration

-In 1990s Tesla Test Facility (TTF) setup at DESY

-2001 TESLA TDR of a Linear Collider with integrated XFEL

-2002 Supplement to the TDR on a dedicated linac for the XFEL, negotiations started to build the XFEL as European project at DESY

-2006 TDR of the European XFEL

-June 5, 2007 official launch of the project

-First beam expected for 2013

-2004 ITRP recommended superconducting technology for a future Linear Collider

-Many of the developments for TESLA and the XFEL might be used for the ILC 


\section{Introduction}

Linac energy:

Wavelength:

Beam pulse length:

Repetition rate:

\# of bunches in pulse:

Bunch to bunch spacing:

Bunch charge:

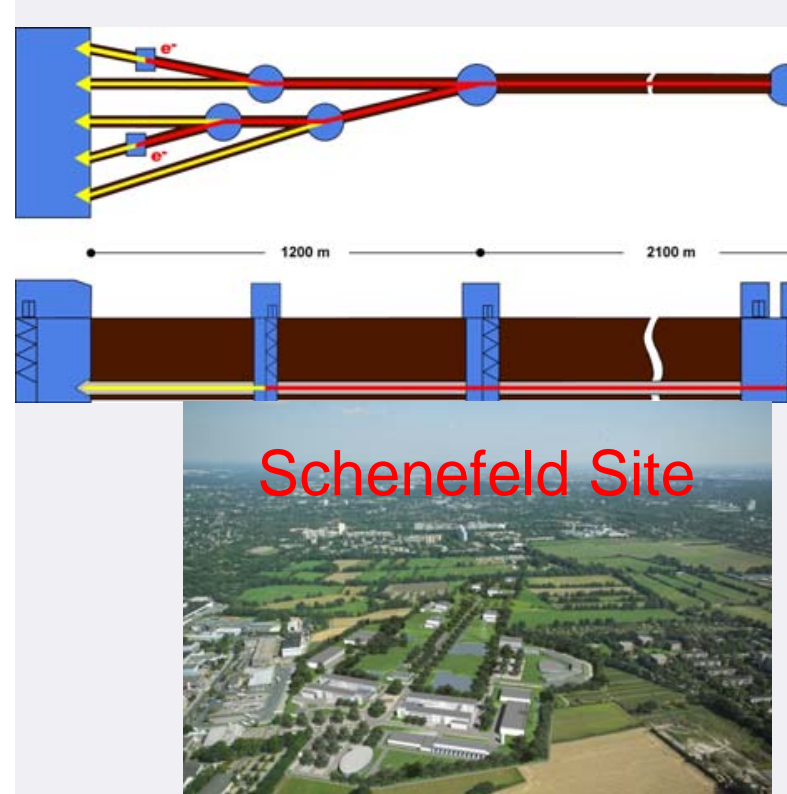

Stefan Choroba, DESY PAC2007, June 26, 2007
$17.5 \mathrm{GeV}(20 \mathrm{GeV})$ down to $0.1 \mathrm{~nm}$ $650 \mu \mathrm{s}$ $10 \mathrm{~Hz}(30 \mathrm{~Hz}$ at lower energy)

3250

200ns

$1 \mathrm{nC}$

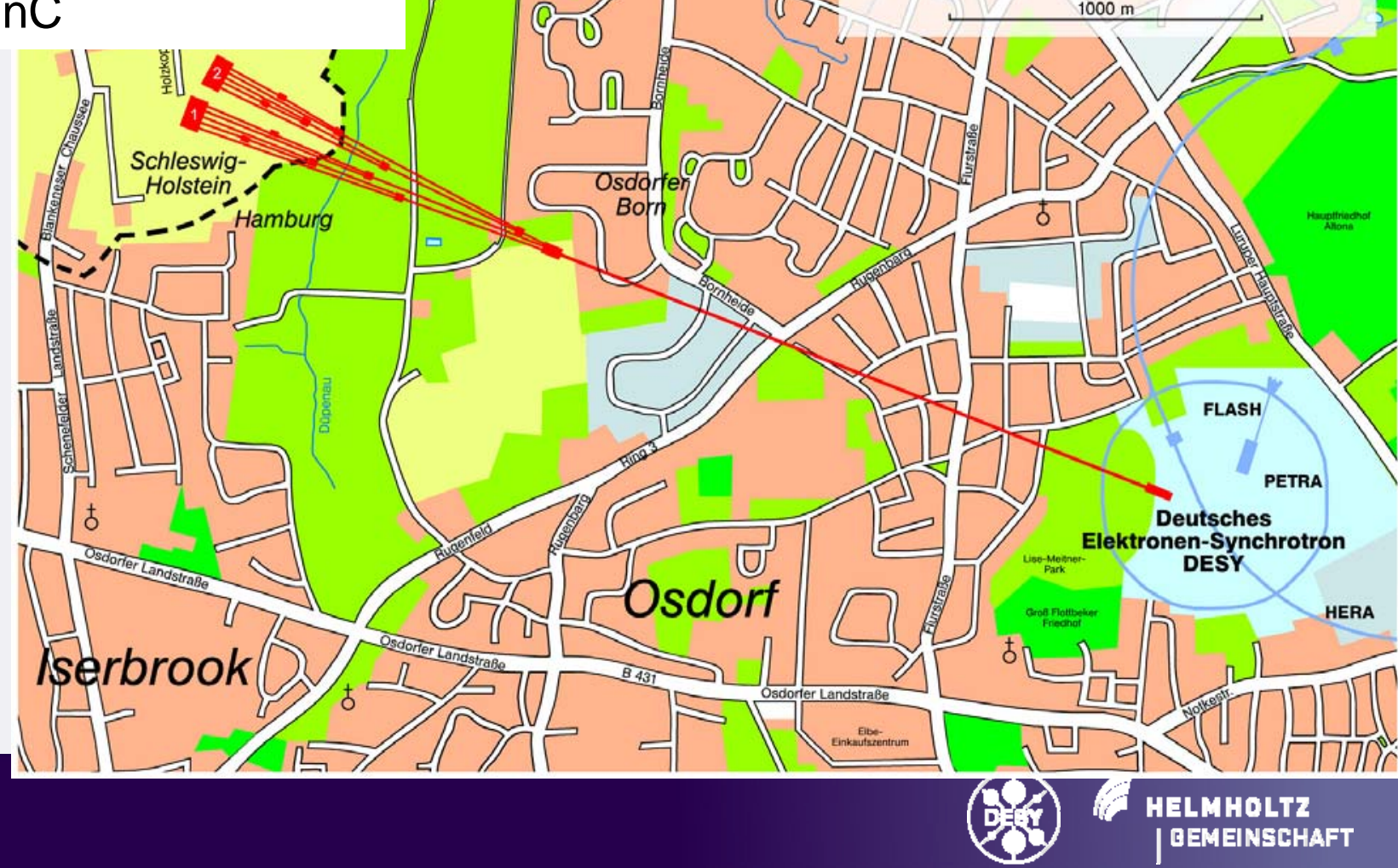




\section{RF System Requirements}

Number of sc cavities:

Power per cavity:

Gradient at $17.5 \mathrm{GeV}$ :

Power per 32 cavities

(4 cryo modules):

Power per RF station:

Number of RF stations:

Number of RF stations for injectors:

Macro beam pulse duration:

RF pulse duration:

Repetition rate:

Average RF power per station:
800 (928) total for $17.5 \mathrm{GeV}(20 \mathrm{GeV})$

$122 \mathrm{~kW}$

$23.6 \mathrm{MV} / \mathrm{m}$

3.9MW

5.2MW (including 10\% losses in waveguides and circulators and a regulation reserve of $15 \%$ )

25 (29), active 23 (26)

2

$650 \mu \mathrm{s}$

$1.38 \mathrm{~ms}$

$10 \mathrm{~Hz}(30 \mathrm{~Hz})$

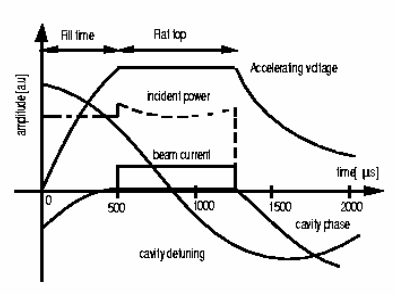

$72 \mathrm{~kW}(150 \mathrm{~kW})$ 


\section{RF System Requirements}

\section{Layout of one RF Station}

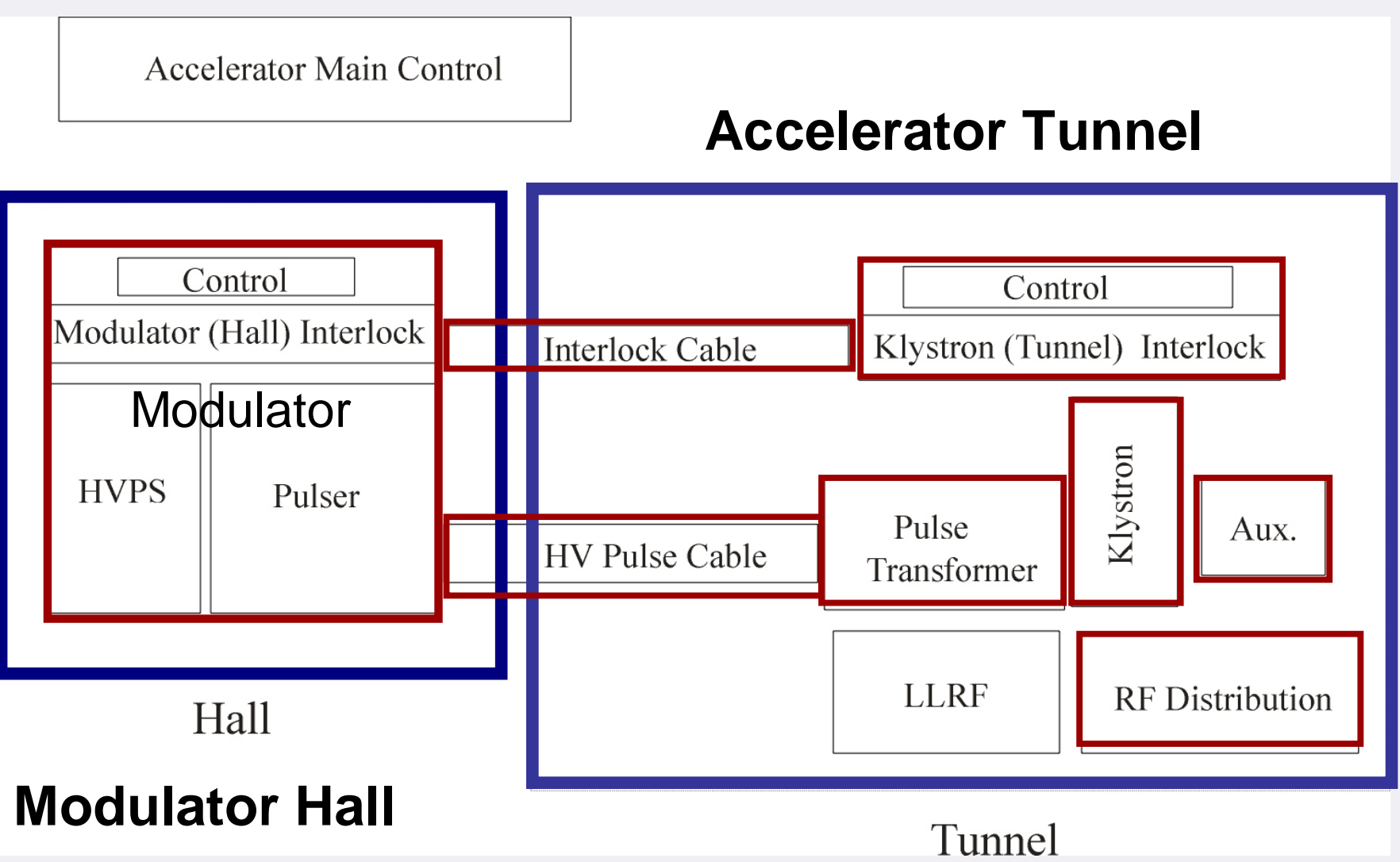




\section{RF System Requirements}

\section{Layout of the RF Station in the Accelerator Tunnel}

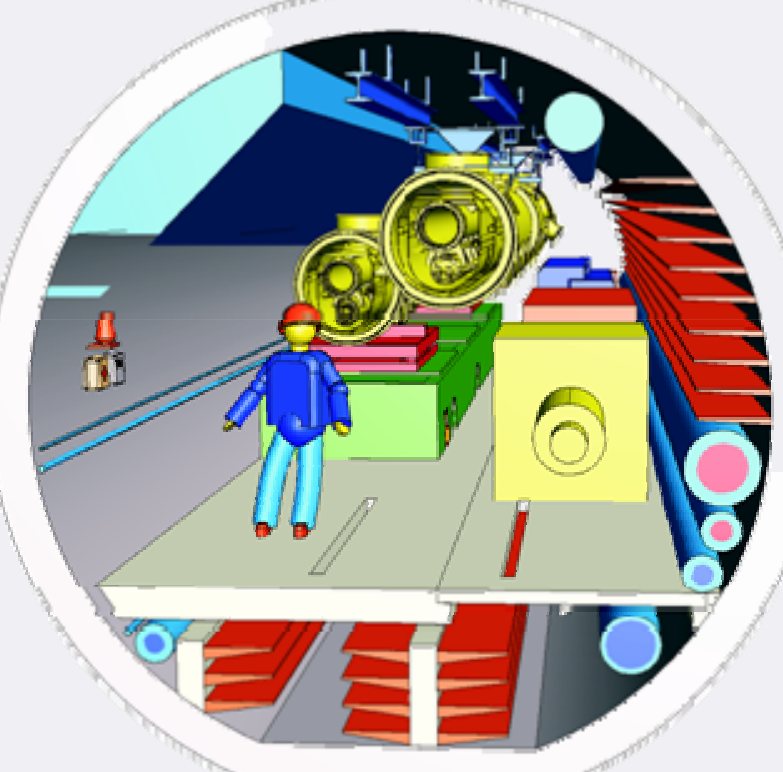

-Tunnel components (klystrons, pulse transformers, aux. power supplies etc.) will be installed under the cryogenic module.

-The waveguide distribution will be installed on the side of the cryo module.

-These components are not accessible during accelerator operation. 


\section{RF System Requirements}

\section{Layout of the RF Station in the Modulator Hall}

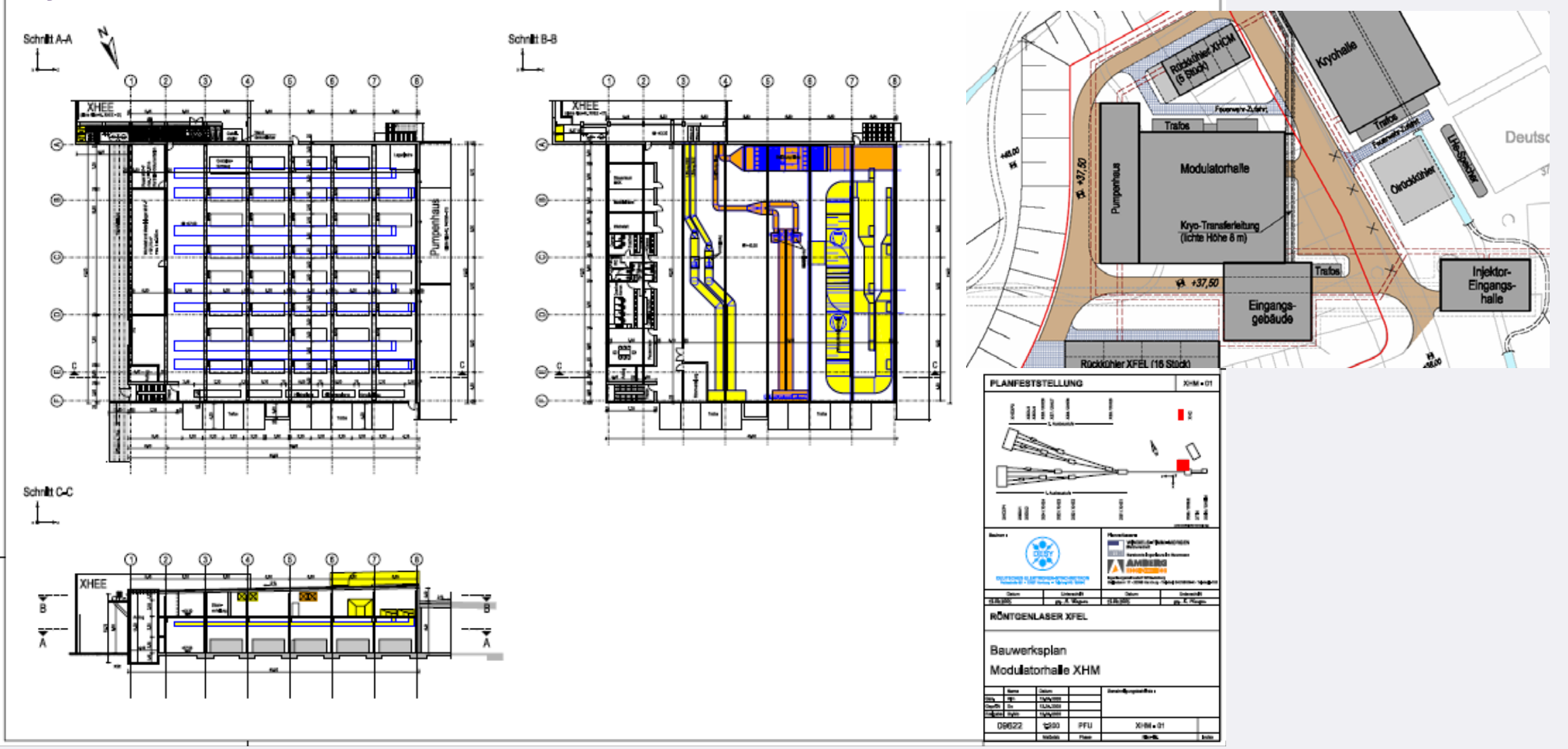

- The modulators will be installed in the modulator hall.

-Maintenance and repair is possible during accelerator operation. 


\section{RF High Power Source}

\section{Requirements}

Operation Frequency:

Cathode Voltage:

Beam Current:

Max. RF Peak Power:

RF Pulse Duration:

Repetition Rate:

RF Average Power:

Efficiency:

Solenoid Power:

Length:

Multibeam Klystrons (MBK) have been chosen
1.3GHz

$<120 \mathrm{kV}$

$<140 \mathrm{~A}$

$10 \mathrm{MW}$

$1.5 \mathrm{~ms}$

$10 \mathrm{~Hz}$

$150 \mathrm{~kW}$

$65 \%$

$<5.5 \mathrm{~kW}$

$2.5 \mathrm{~m}$

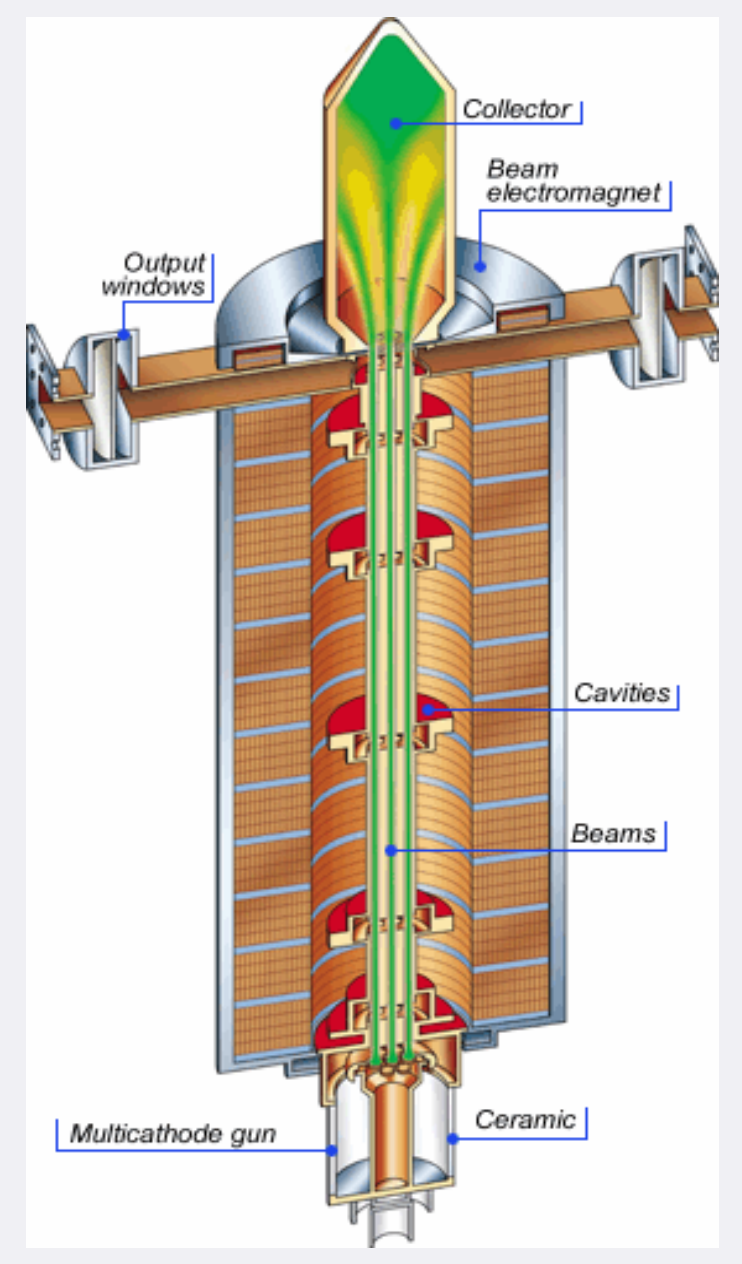




\section{RF High Power Source}

3 klystron vendors have developed MBKs during the last years

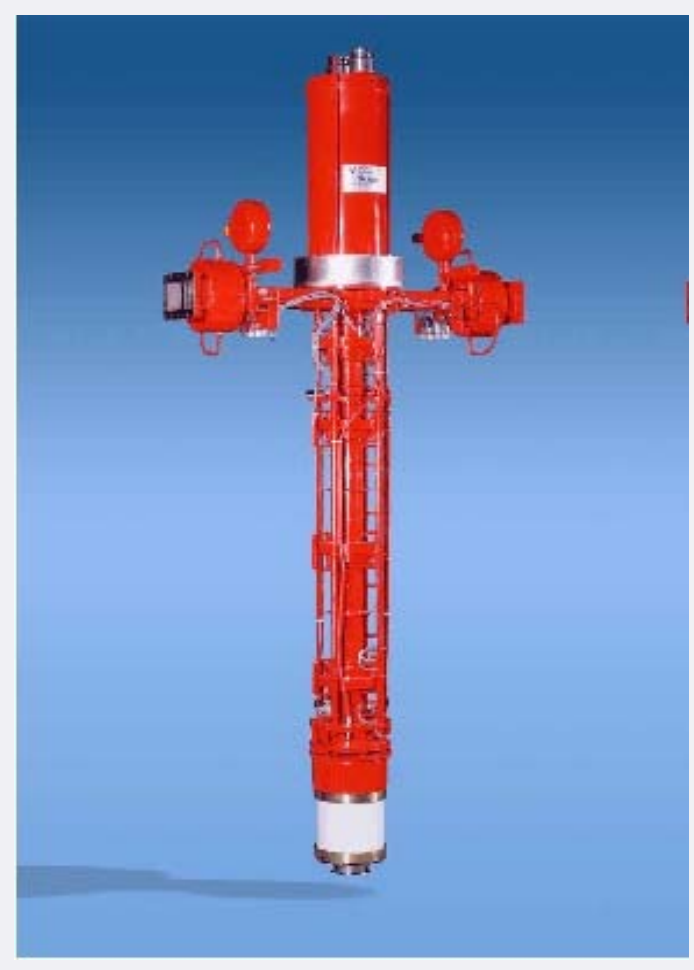

THALES TH1801

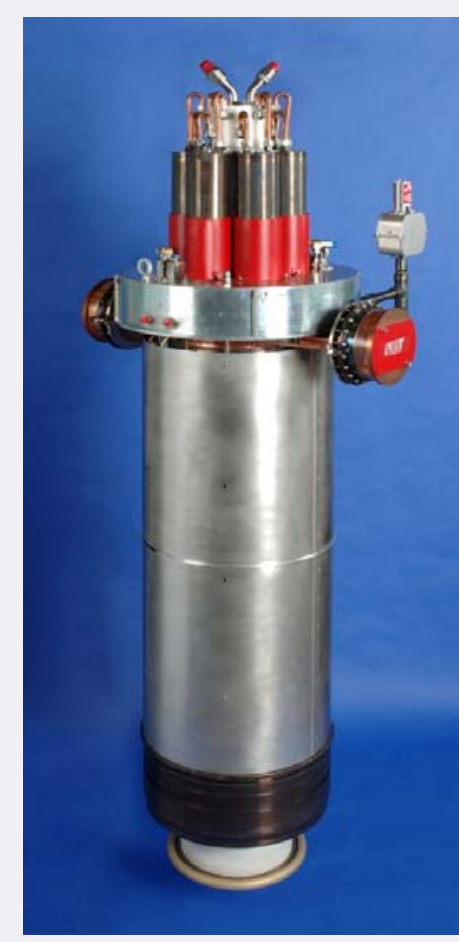

CPI VKL8301

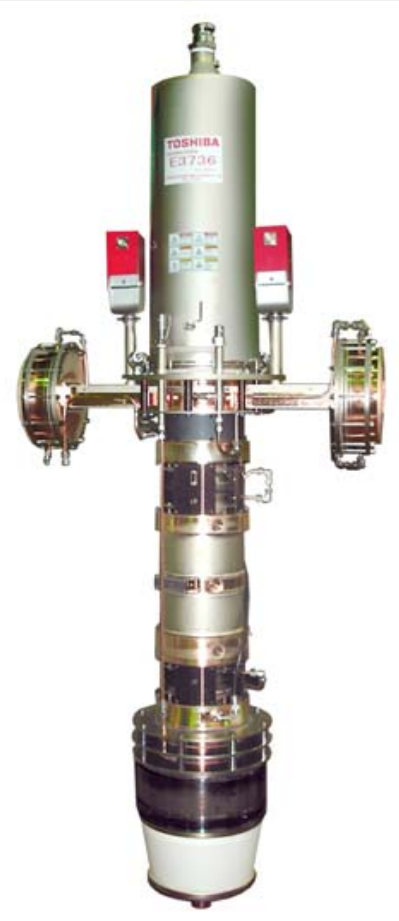

TOSHIBA E3736 


\section{RF High Power Source}

\section{Status of vertical MKB development}

- 6 THALES TH1801 have been built, the last one has been tested successfully at THALES recently

- best $10 \mathrm{MW}, 1.5 \mathrm{~ms}, 10 \mathrm{~Hz}, 65 \%$ on matched load

- typical 10MW, 1.5ms, $10 \mathrm{~Hz}, 63 \%$

- klystrons in use at FLASH, PITZ, MBK test stand

- several thousand hours of operation at different conditions

- modifications have been made after early failures => no signs of degradation anymore

- 1 TOSHIBA E3736 at DESY

- 10.4MW, $1.5 \mathrm{~ms}, 10 \mathrm{~Hz}, 66 \%$

- 750h, 80\% at full power

- $1 \mathrm{CPI}$ VKL8301 at DESY

- 8.1MW, $1.3 \mathrm{~ms}, 10 \mathrm{~Hz}, 53.5 \%$ 


\section{RF High Power Source}

\section{Horizontal MBK prototypes}

-Horizontal versions of MBKs by all 3 vendors are under construction (THALES, TOSHIBA, CPI) -First klystron expected for second half of 2007

THALES TH1802

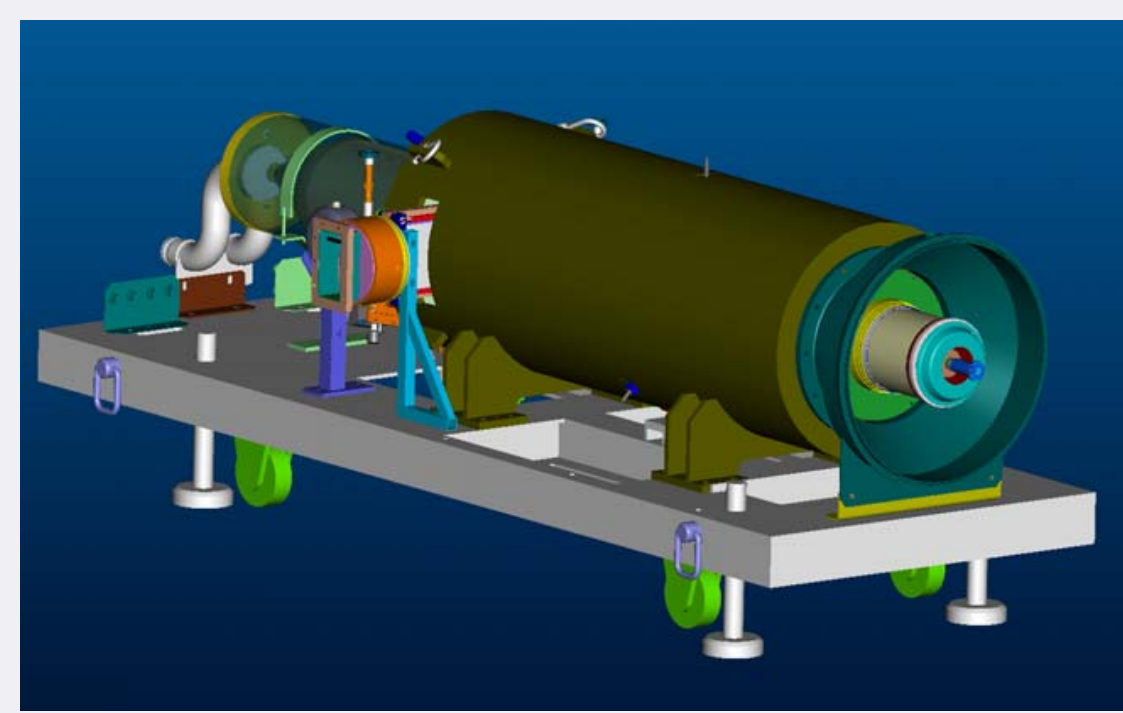

TOSHIBA E3736H

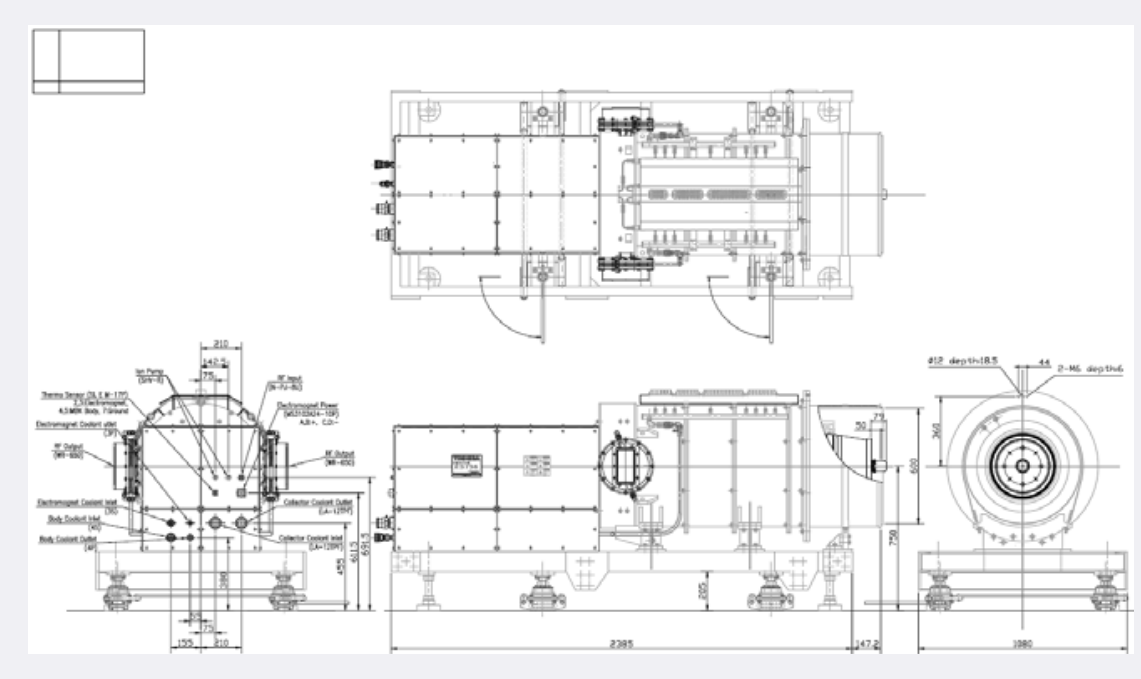




\section{Modulator}

\section{Modulator Requirements}

-Modulators must generate HV pulses up to $120 \mathrm{kV}$ and $140 \mathrm{~A}, 1.57 \mathrm{~ms}$ pulse length and $10 \mathrm{~Hz}(30 \mathrm{~Hz})$ repetition rate

-The top of the pulse must be flat within $1 \%$

-The bouncer type modulator with its simple circuit diagram was chosen

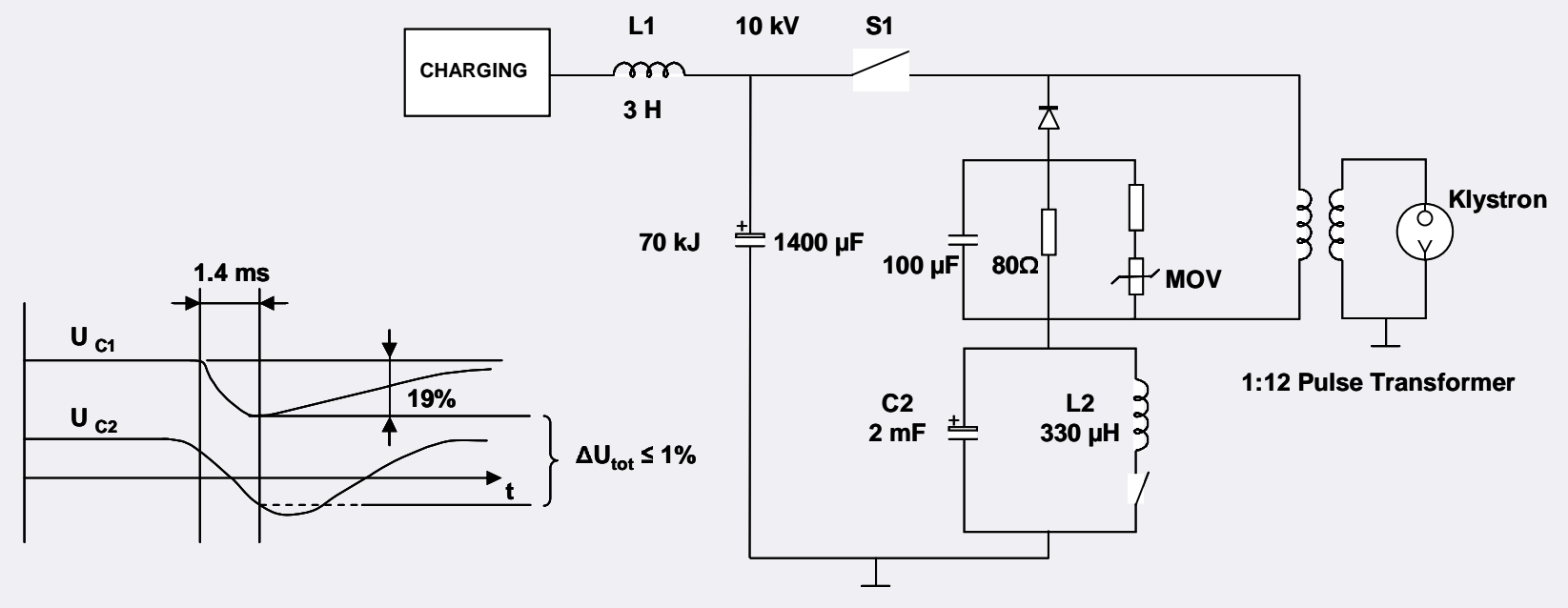




\section{Modulator}

\section{Bouncer Modulator}

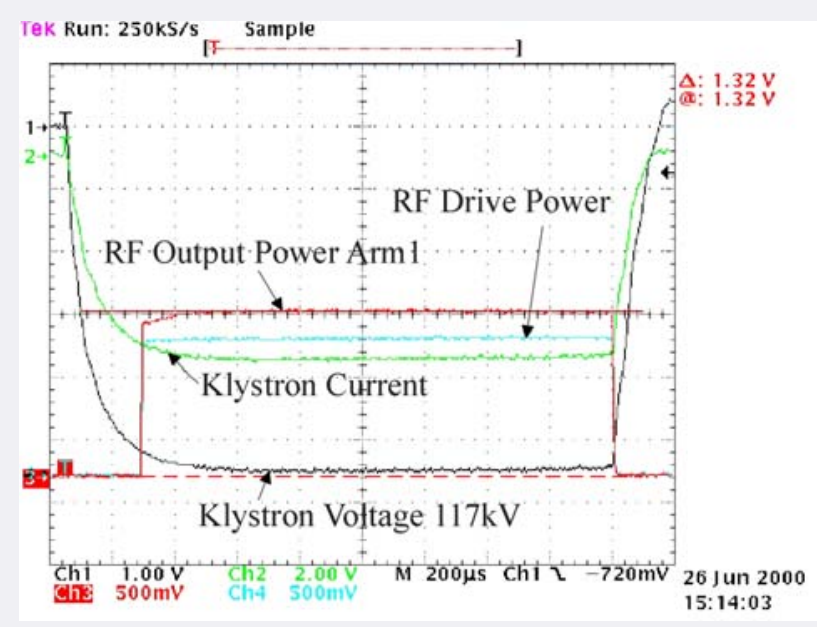

- 3 modulators have been developed, built and delivered to TTF by FNAL since 1994

-They are continuosly in operation at different operation conditions

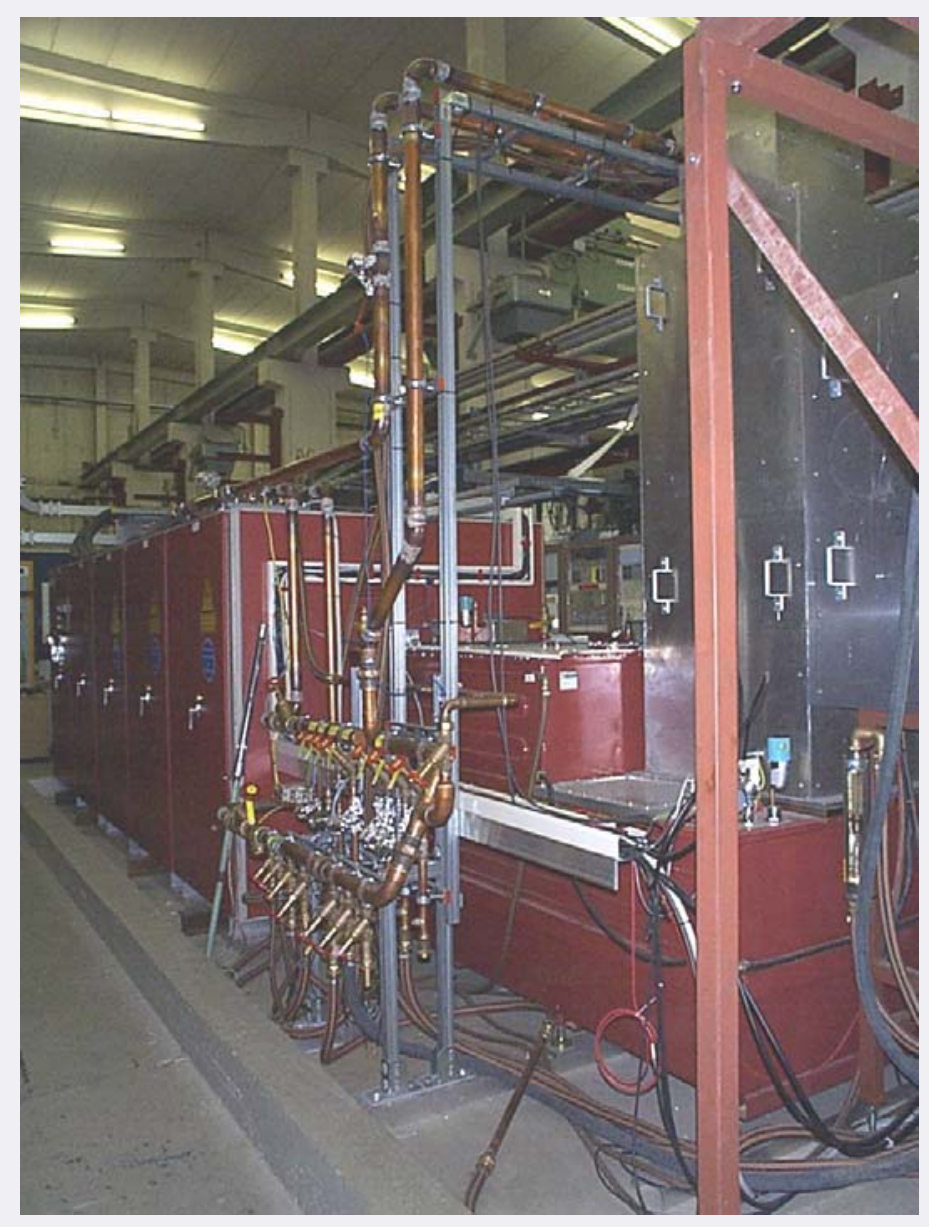




\section{Modulator}

\section{Bouncer Modulator}

-Industry made subunits (PPT, ABB, FUG, Poynting)

-Constant power power supply for suppression of $10 \mathrm{~Hz}$ repetition rate disturbances in the mains

-Compact storage capacitor bank with self healing capacitors

-IGCT Stack (ABB); 7 IGCTs in series, 2 are redundant

- Low leakage inductance pulse transformer (ABB) $\mathrm{L}<200 \mu \mathrm{H}$ resulting in shorter HV pulse rise time of $<200 \mu s$

- Light Triggered Thyristor crowbar avoiding mercury of ignitrons
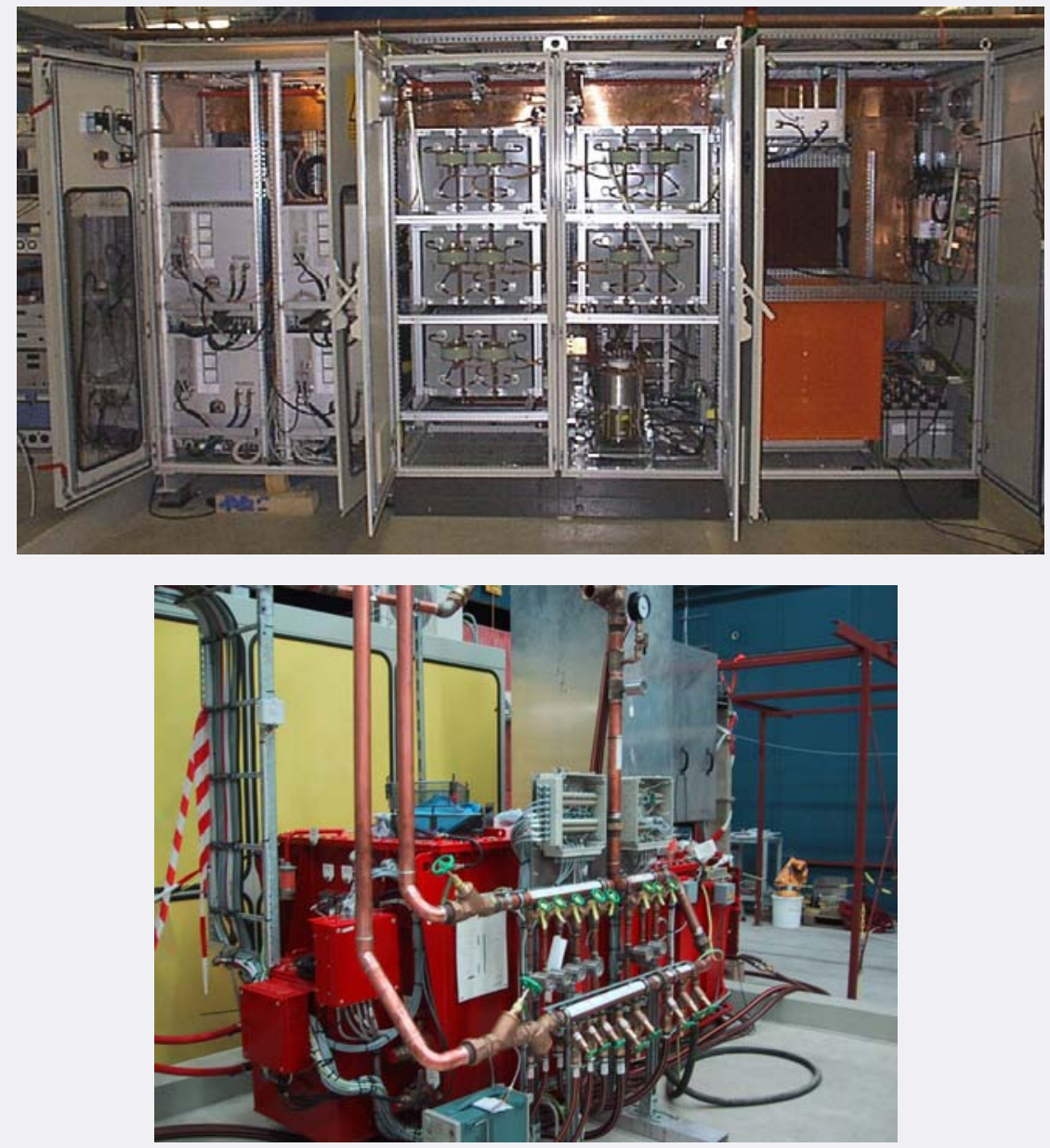


\section{Modulator}

\section{Planned Modulator Test Facility at DESY in Zeuthen}

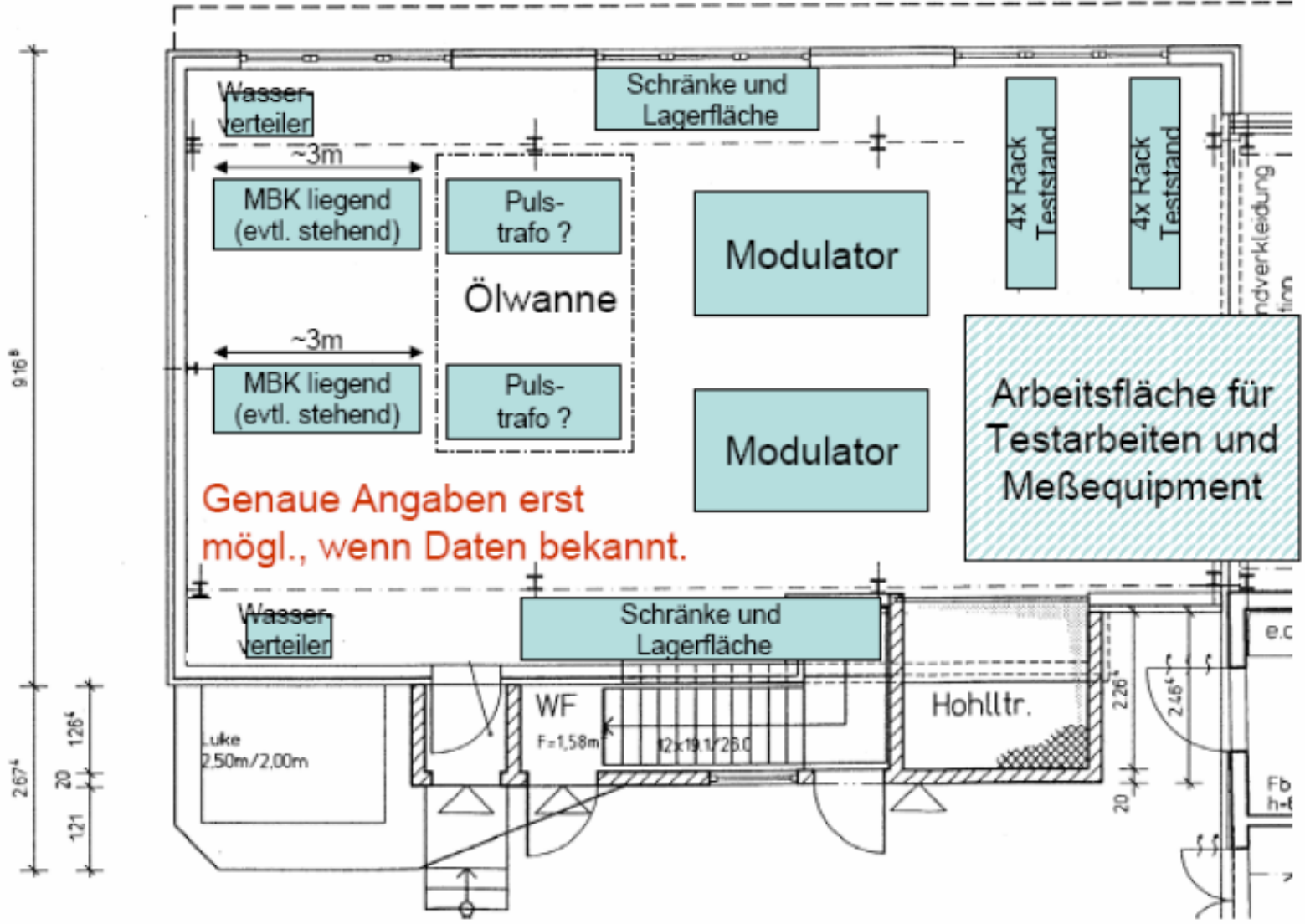




\section{Modulator}

\section{Qualification of additional vendors}

\section{Bouncer Modulator by Imtech/Vonk}

- Bouncer Type, as specified by DESY

- 12kV HVPS

- Bouncer 300uH/4.6kA ${ }_{690 \mathrm{Vac}}$ HVPS

- 7st IGCT main switch

- Digital Regulation Circuit

- Analog In- and Outputs

- Well known and tested principle

- delivery time: 12 month

\section{PSM Modulator by Thomson BM}

- Different Type:

- 12kV/2kA w. transformer

- Pulse Width Modulation

- 24 switching stages in series

- FPGA based control

- 2 stages for redundancy

- Slew rate and pulse shape controllable

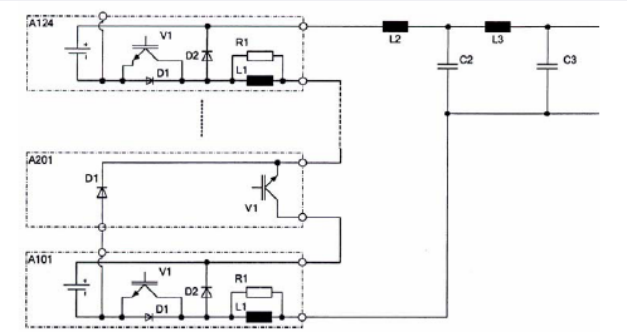

- detailed description available, principle already successfully tested (worldwide, i.e. W7/X)

- delivery time: 14 month

Installation at DESY, location Zeuthen, scheduled for spring 2008 


\section{Modulator}

\section{HV Pulse Cable}

-Transmission of HV pulses (10kV, 1.6kA, $1.57 \mathrm{~ms}, 10 \mathrm{~Hz}(30 \mathrm{~Hz})$ ) from the pulse generating unit (modulator hall) to the pulse transformer (accelerator tunnel)

-Maximum length $1.5 \mathrm{~km}$

-Impedance of 25 Ohms (4 cables in parallel will give 6.25 Ohms in total) to match the klystron impedance

- Triaxial construction (inner conductor, middle conductor, outer conductor at ground)

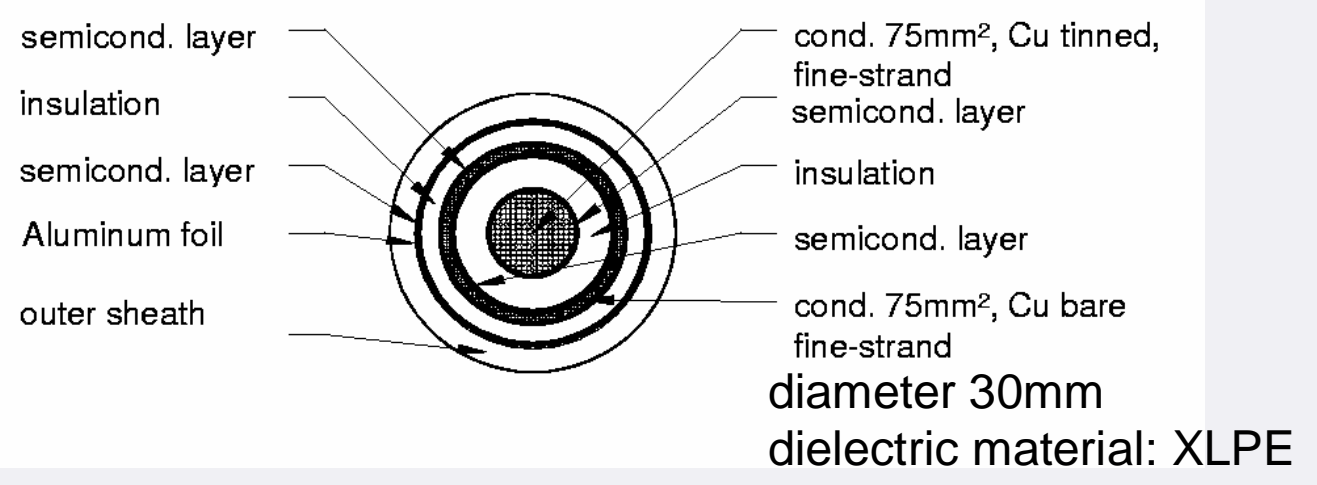




\section{Modulator}

\section{HV Pulse Cable Test}

-Pulse transmission has been tested successfully at TTF/FLASH Modulator 5

-EMI caused by cable required modification of modulator internal layout (lower leakage inductances, EMC cabinets, bouncer at high voltage potential)

- New modified modulator is installed at DESY hall 2 and will supply HV pulses via a $1.5 \mathrm{~km}$ long cable to a PT/Klystron in hall

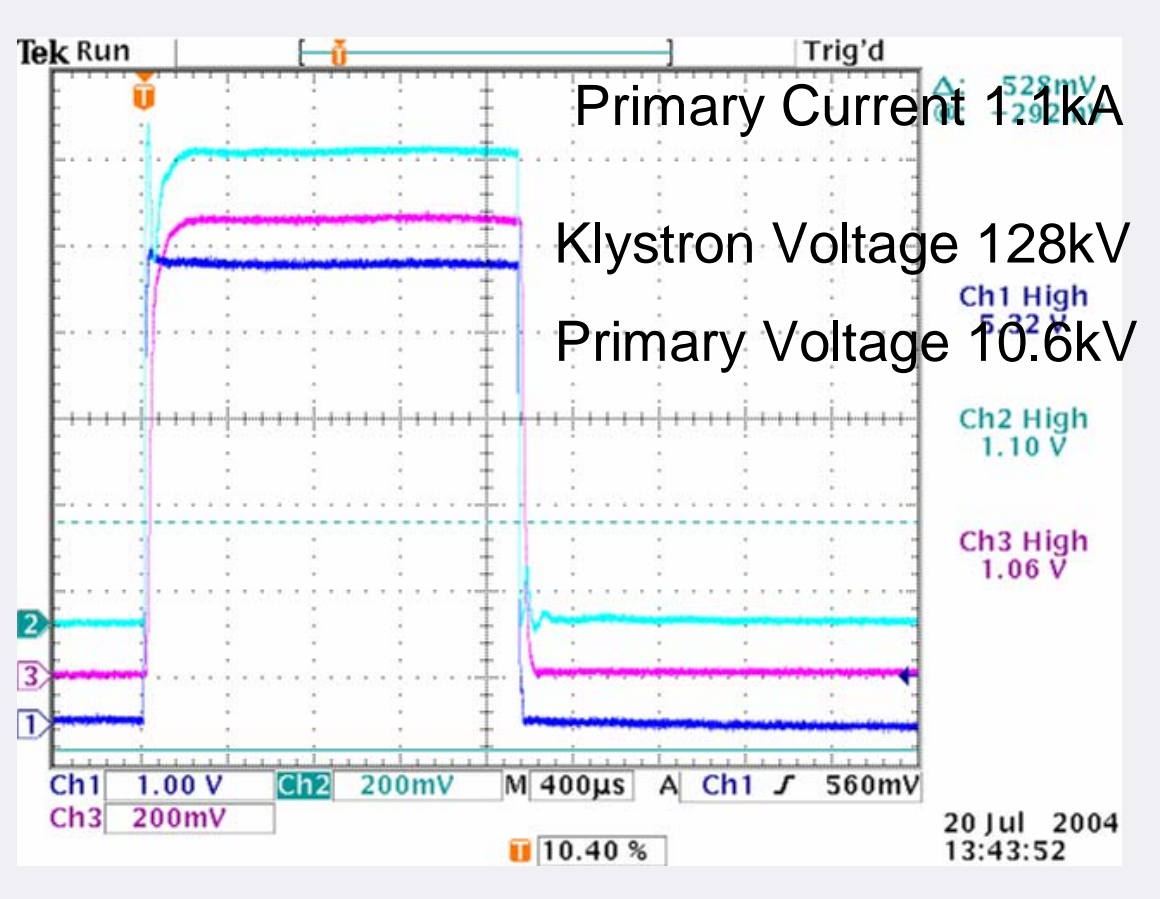
3 (FLASH) during part of the next operation period of FLASH 


\section{Modulator}

\section{Status Modulator}

- 11 bouncer modulators have been built, 3 by FNAL and 8 together with industry

- 11 modulators are in operation (FLASH, PITZ, XFEL test stands)

- More than 10 years of operation experience

- A new modulator is installed in DESY hall 2 and connected to PT and klystron in hall 3 (Bouncer type plus improvements) and will be used for pulse cable tests

- Order for more XFEL prototypes has been placed (1 bouncer type plus 1 PSM type)

- Test of prototypes at DESY, location Zeuthen, scheduled to start spring 2008 


\section{Waveguide Distribution}

- Distribution of klystron output power to the superconducting cavities

- Protection of the klystron from reflected power

- Control of phase

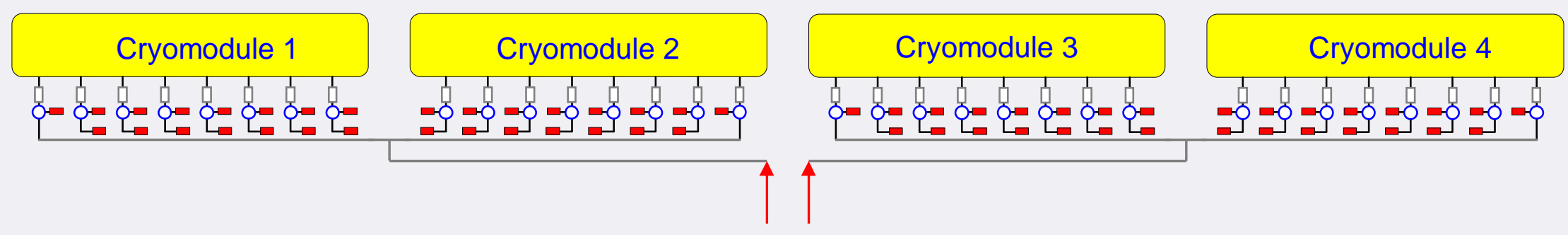

RF from klystron

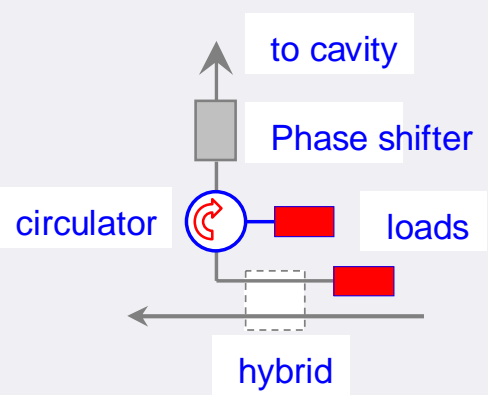




\section{Waveguide Distribution}

Many waveguide components have been developed during the last years and have been used for the operation of TTF/FLASH
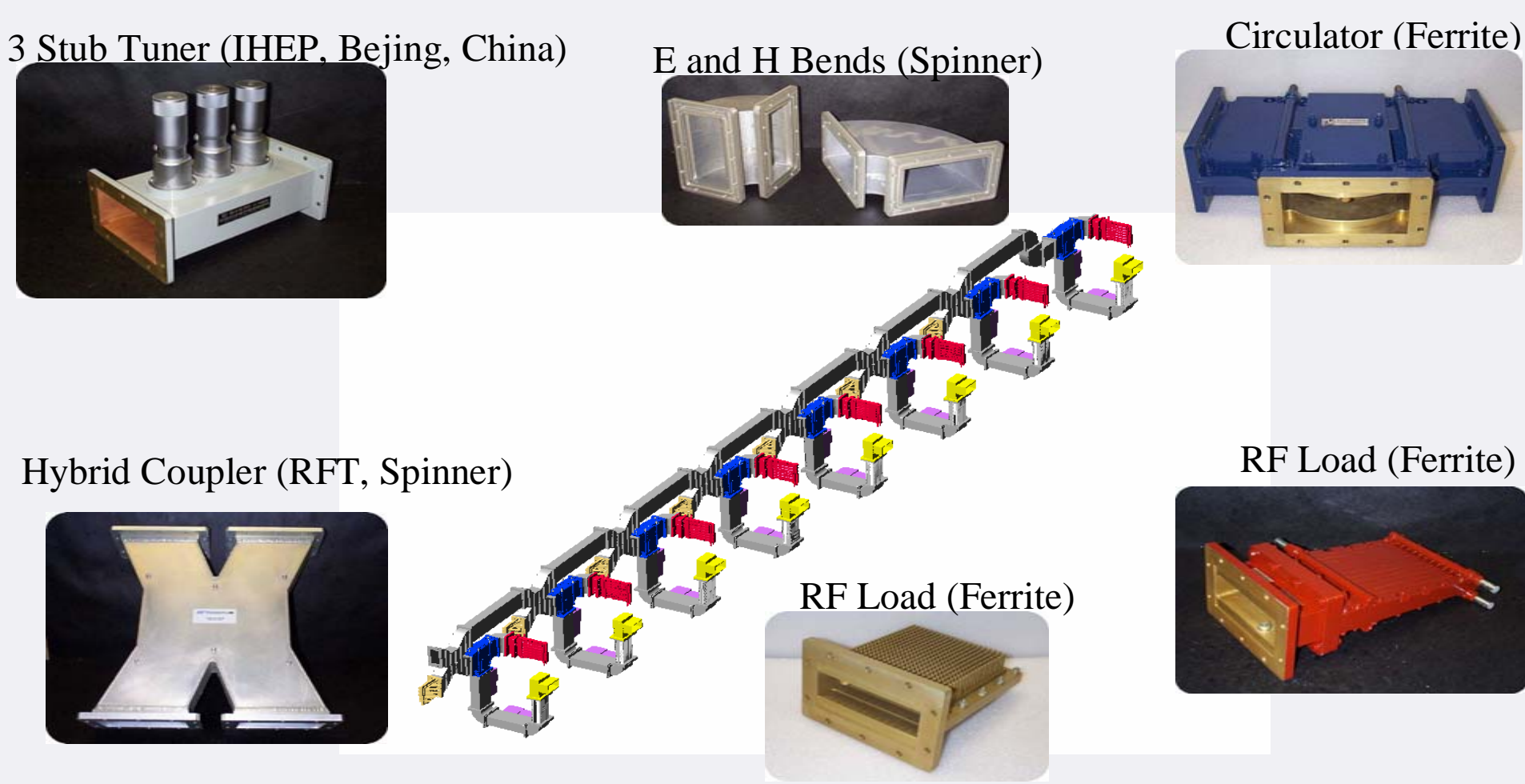

RF Load (Ferrite)

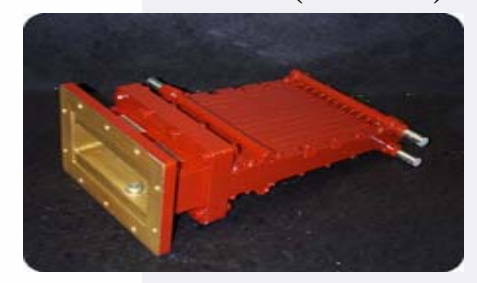




\section{Waveguide Distribution}

- Standard FLASH like distribution (linear system)

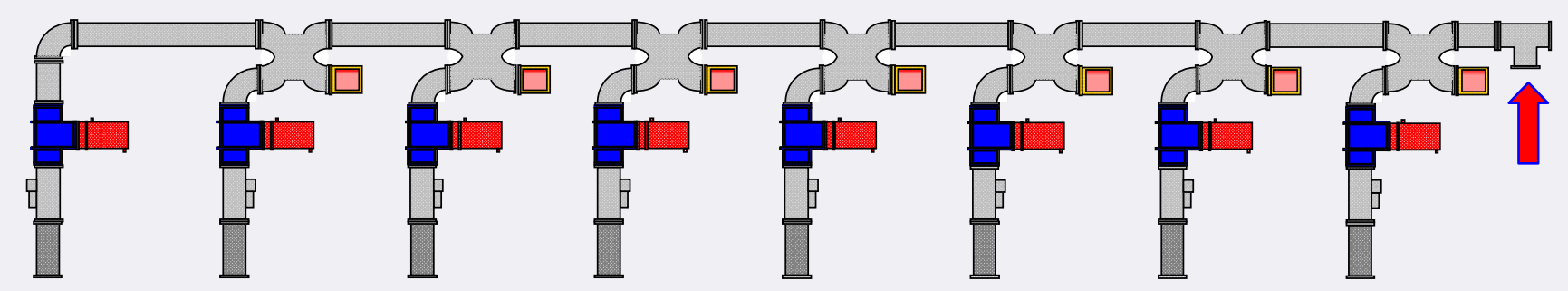

-Combined system with shunt tees (linear system with binary cells)

-Advantages: less space, less parts, less weight, lower costs

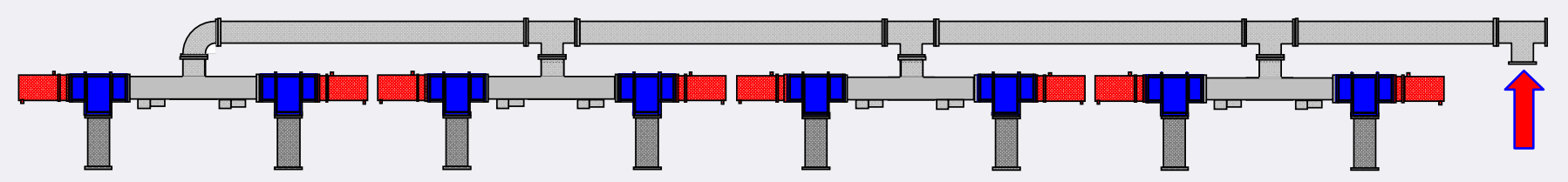

-The new distribution has been tested on a test stand at DESY and will be used with ACC6 at TTF / FLASH 


\section{Waveguide Distribution}

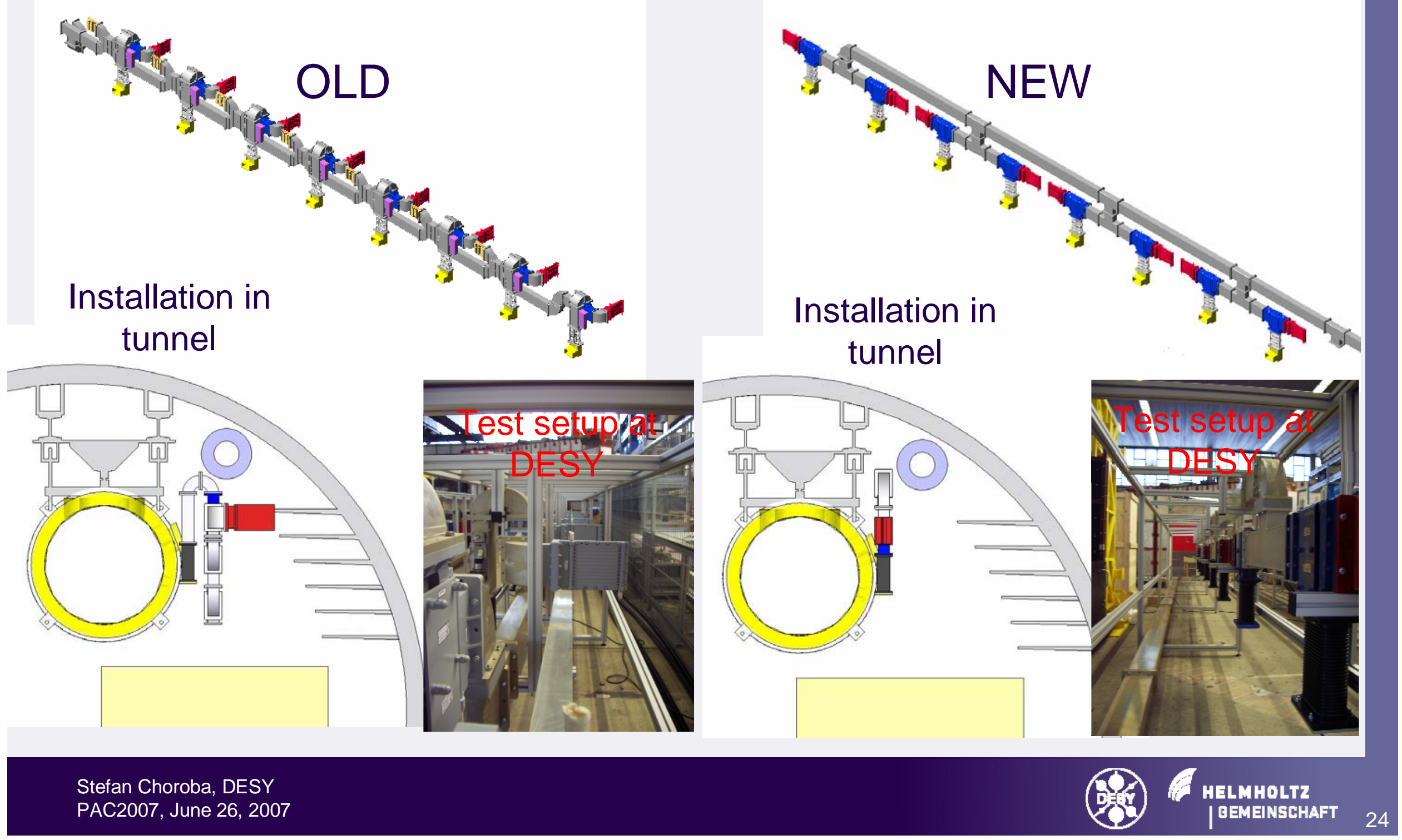




\section{Waveguide Distribution}

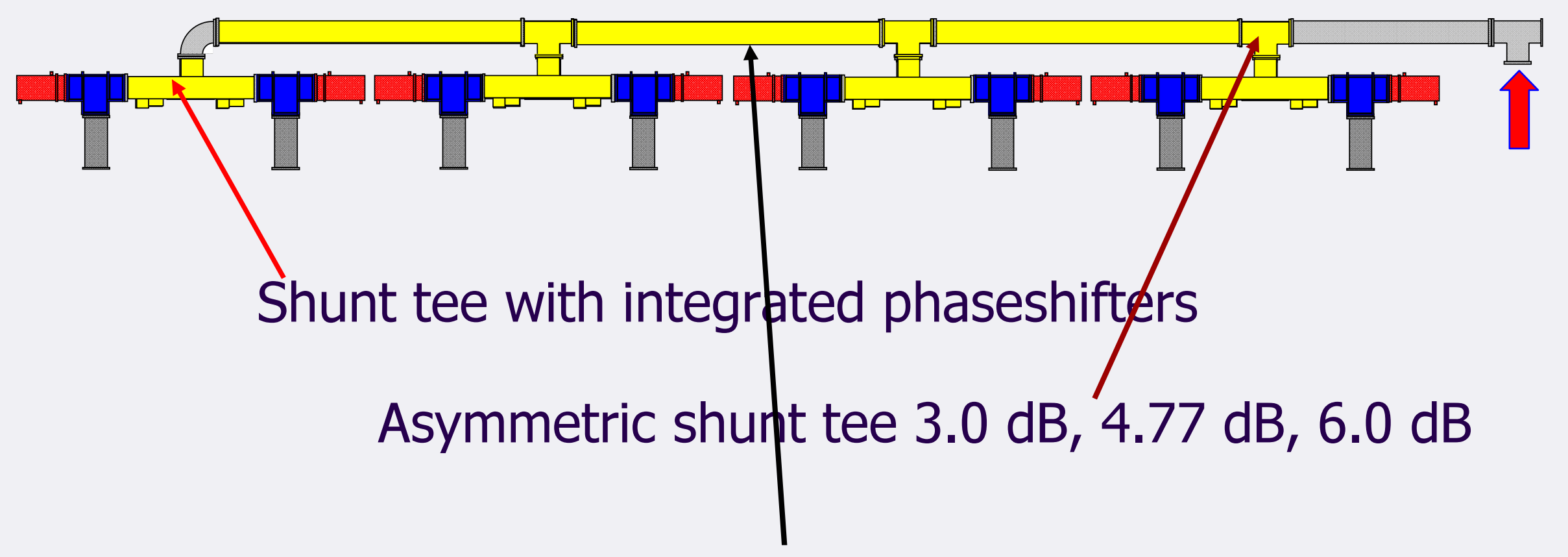

Fixed phase shifters 


\section{Waveguide Distribution}

New binary cell with shunt tee with integrated phase shifter

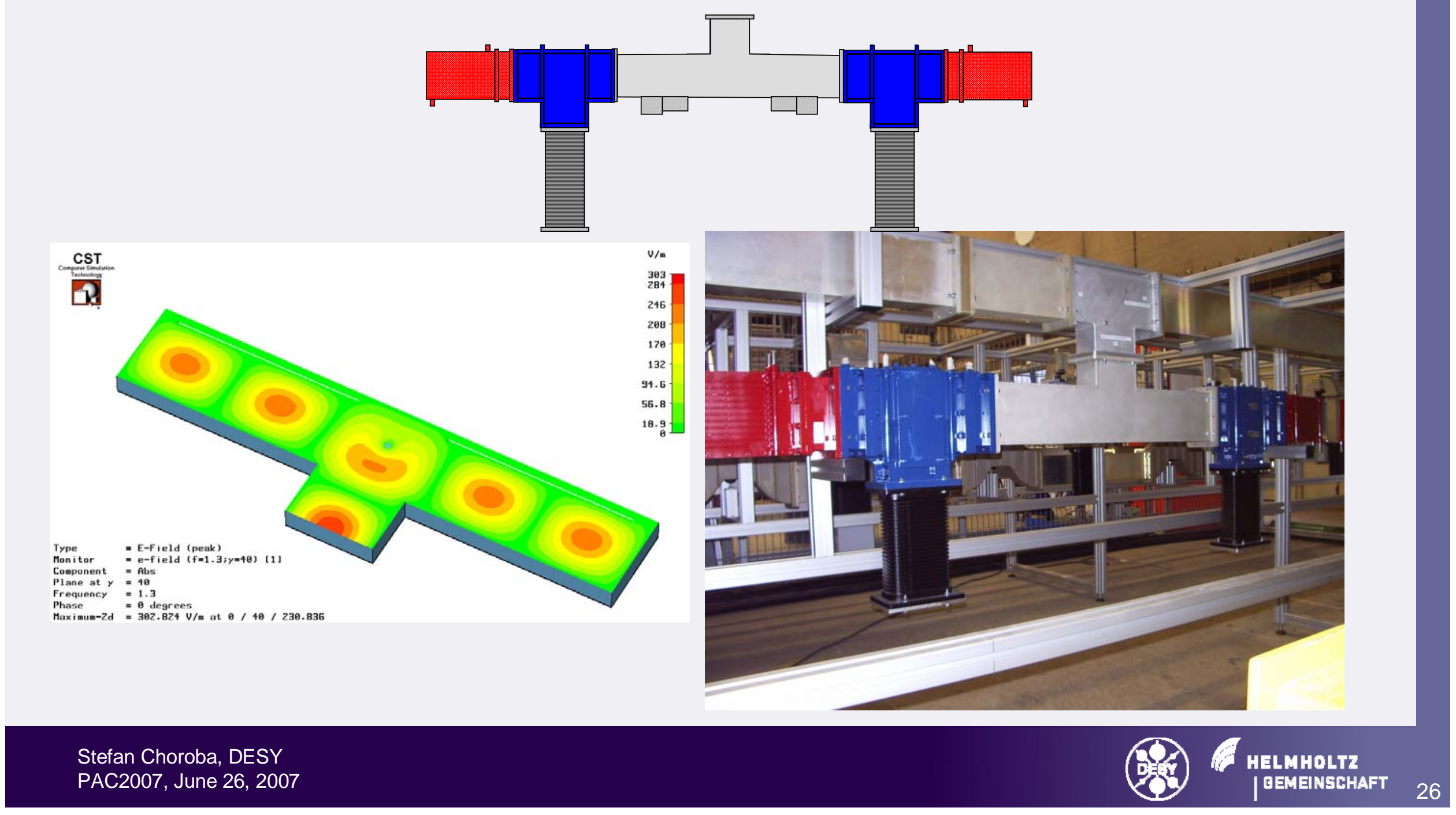




\section{Waveguide Distribution}

\section{Asymmetric shunt tee}

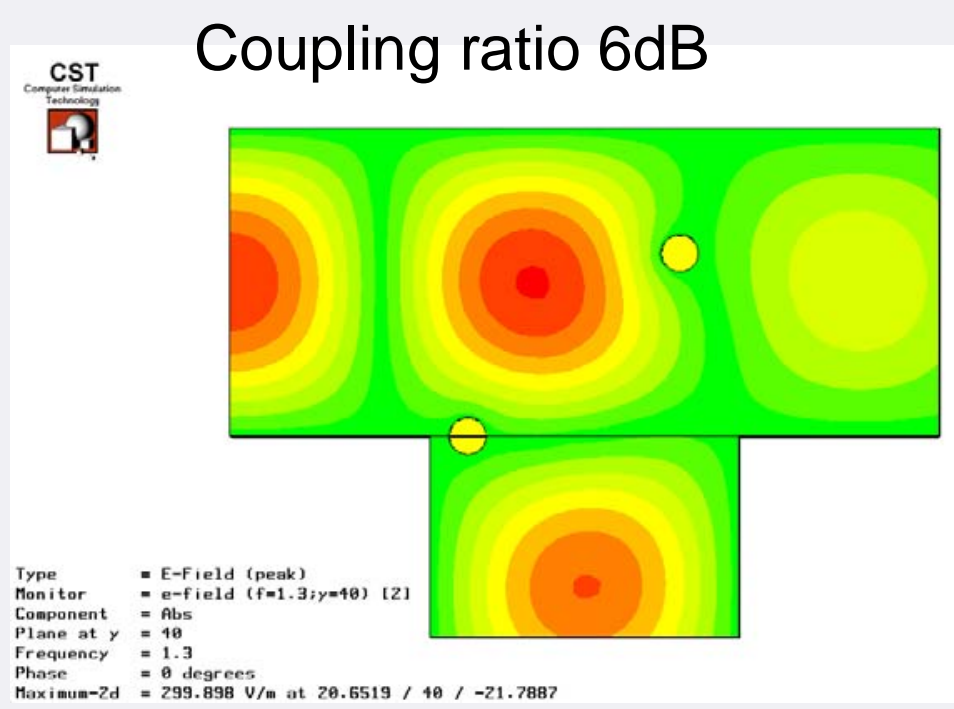

\section{post 1}

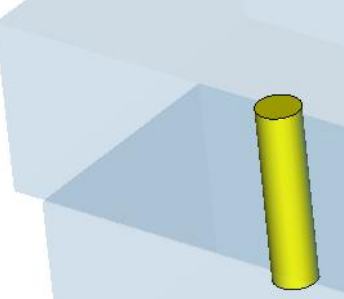

post 2

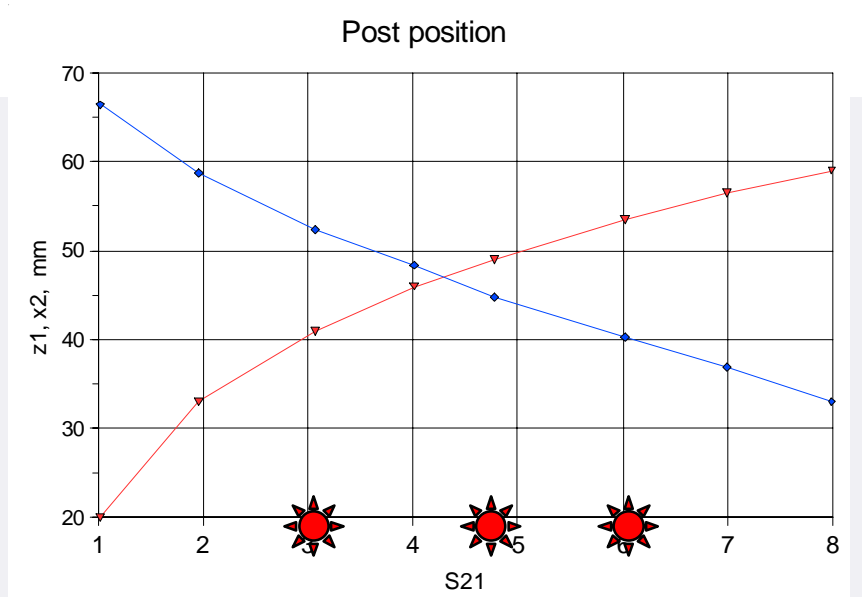




\section{Waveguide Distribution}

\section{Phasing of waveguide distribution}

Combined system with asymmetric shunt tees

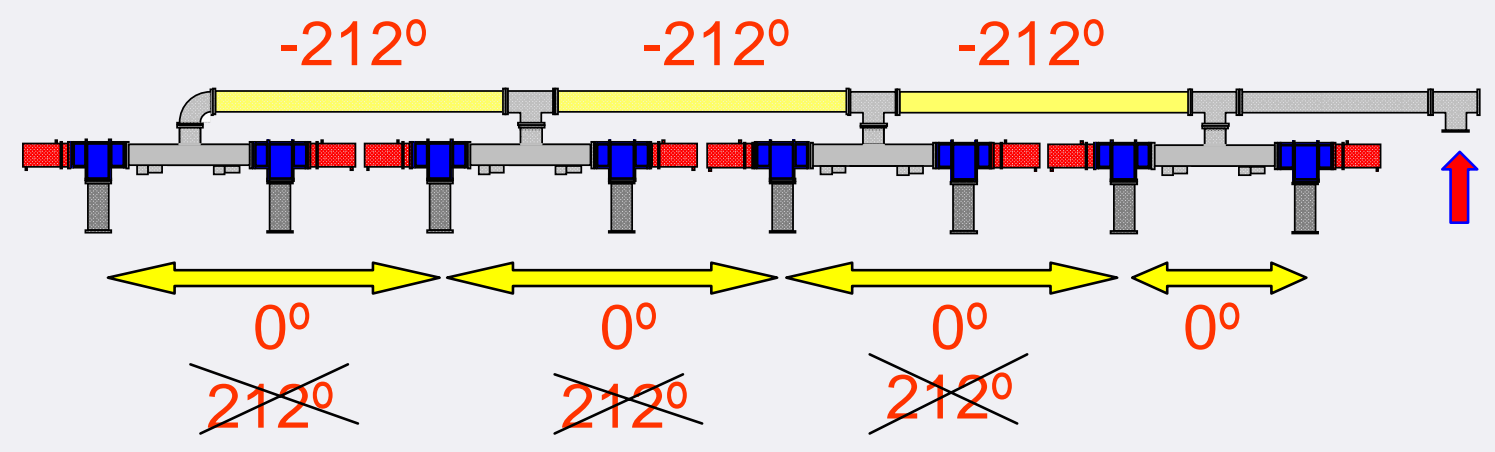

Linear system with hybrids - FLASH like
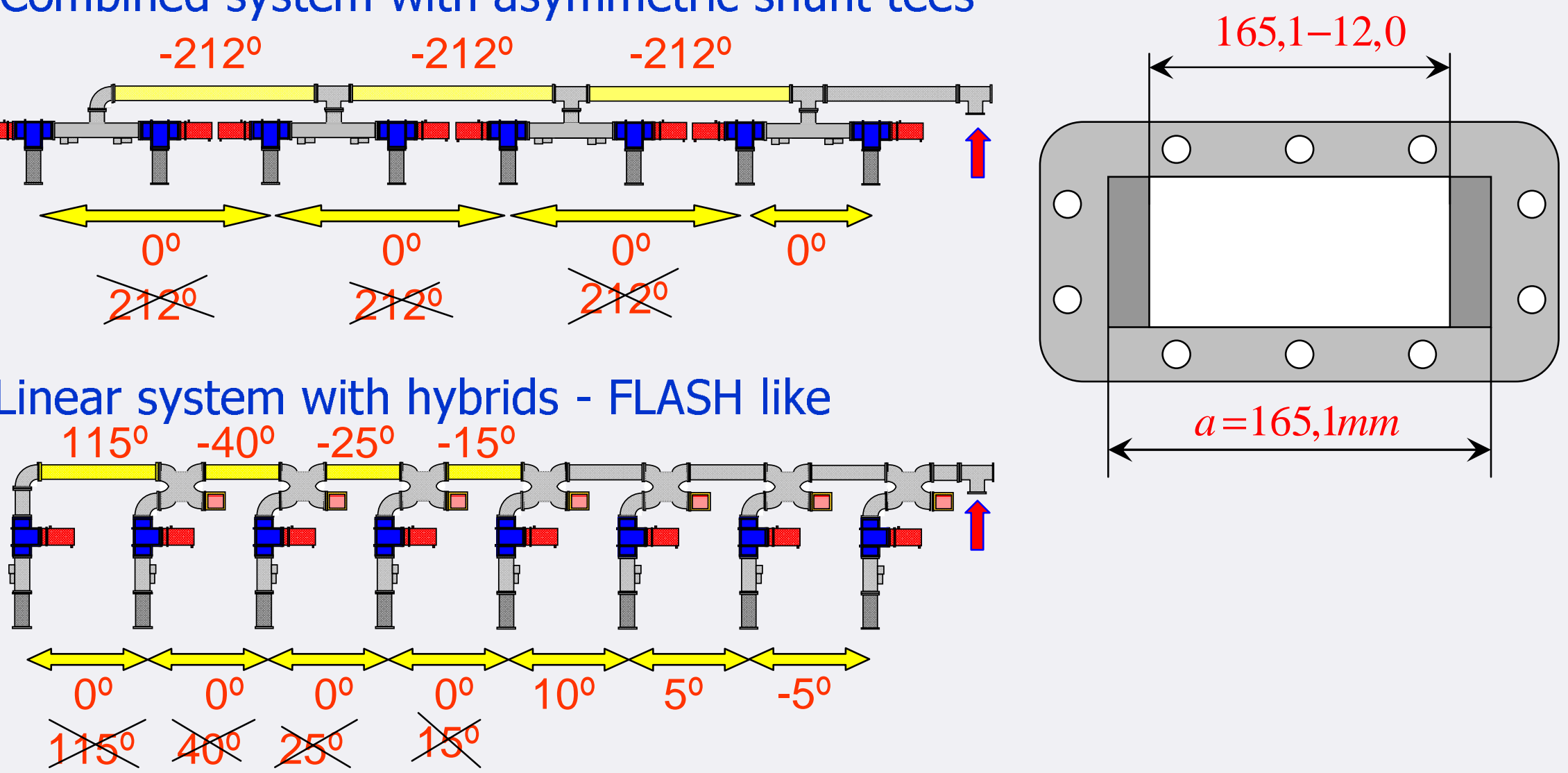


\section{Interlock}

-Modulator interlock is integral part of the modulator

-RF interlock is a DESY

Zeuthen/HH development

-Both parts are connected by glass fibers

-FPGA based

-Version \#2 in use at FLASH at present

-Version \#3 installed at PITZ and module test facility, will be installed at FLASH too

-Version \#3 allows setting of interlocks remote controlled

-The interlock will be installed in shielded racks in the accelerator

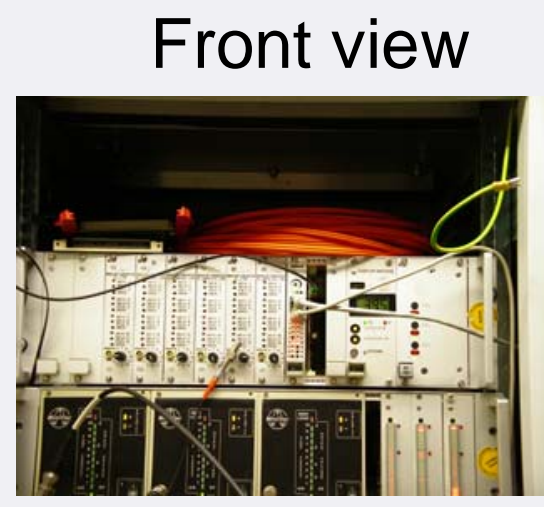

Screen shot

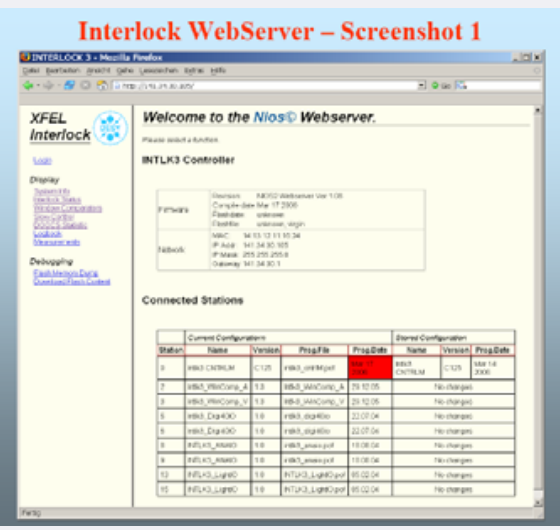

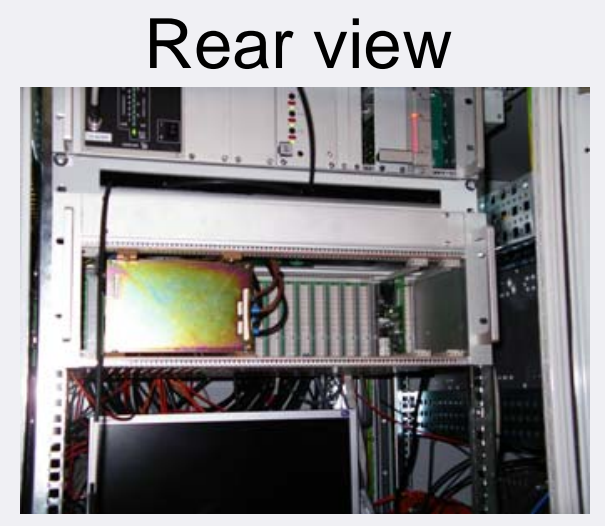

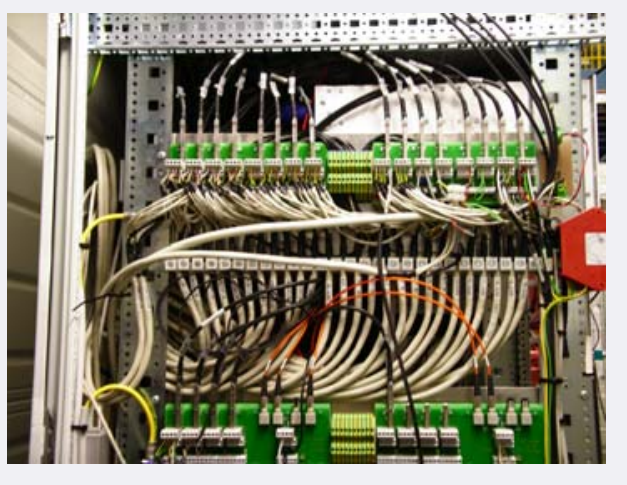
tunnel 


\section{Other Components}

- Off the shelves PS will be used for the klystron solenoid, filament, vacuum pumps and pulse transformer core bias

-A semiconductor preamplifier will be used for amplification of the LLRF signals up to the klystron input level

-Components will be

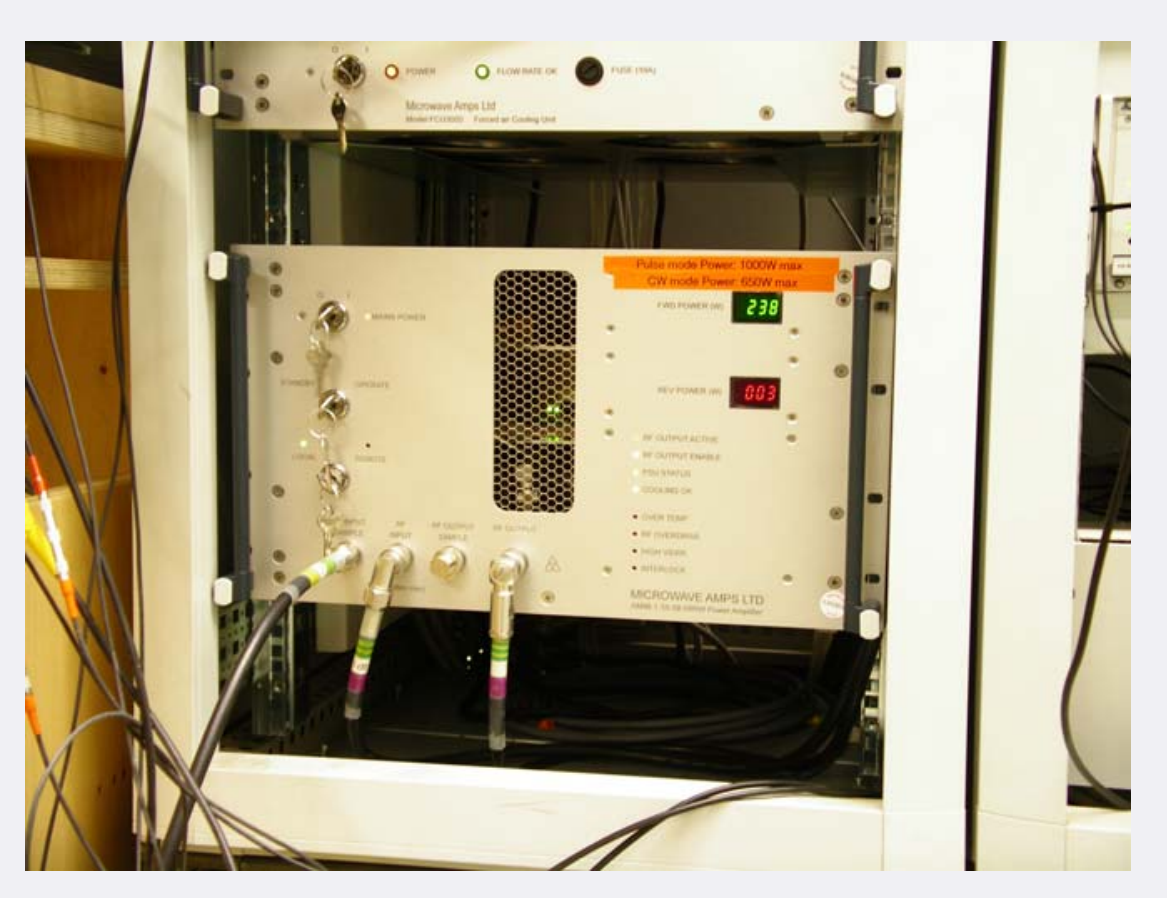
installed in shielded racks in the tunnel 


\section{LLRF}

-Digital system

-Feedback plus feedforward

-Extensive diagnostics and exception handling

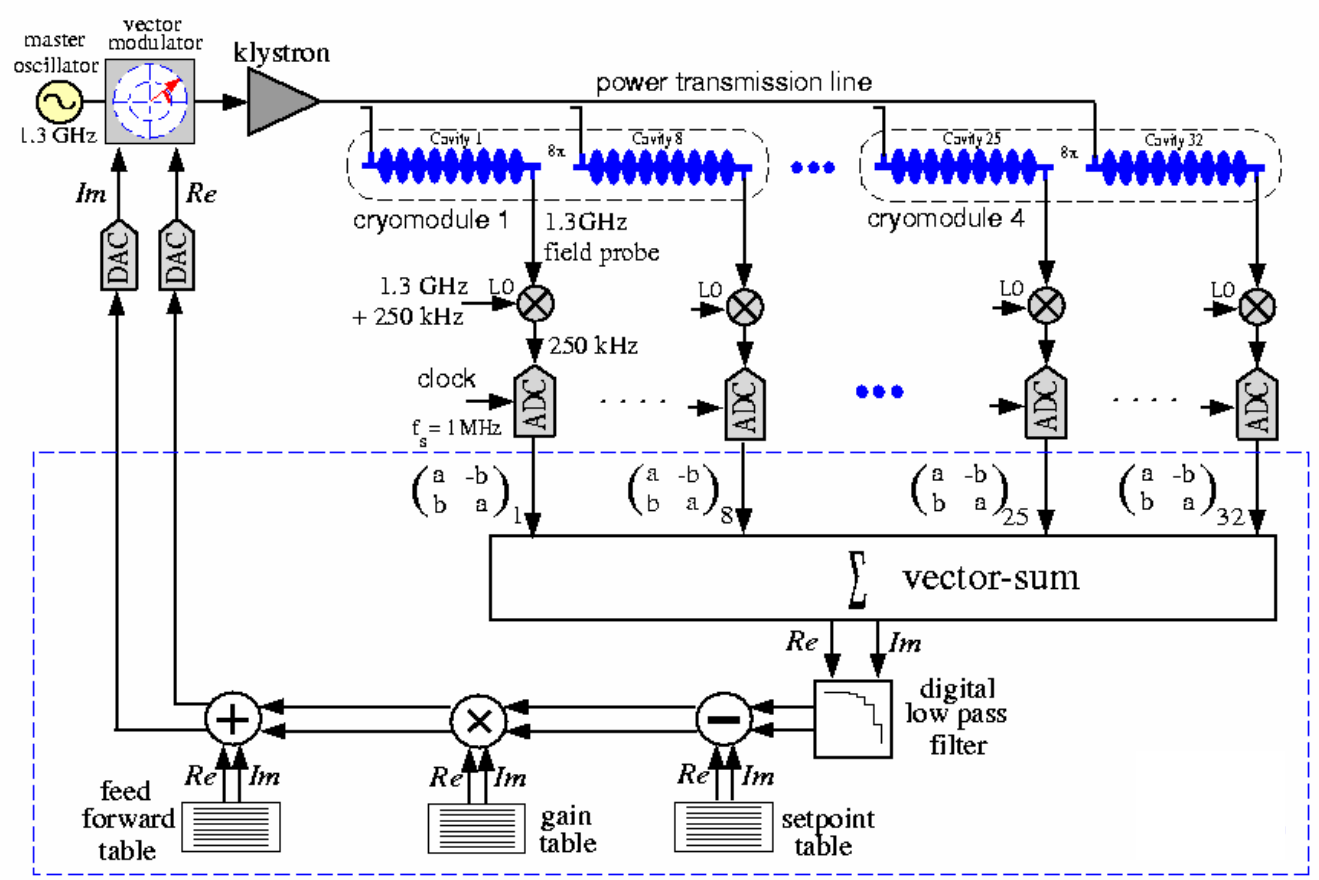




\section{Summary}

- All components for the XFEL RF system have been designed and constructed during the last years.

- Modifications of some components allowing the installation in the accelerator tunnel and qualification of additional vendors are being continued.

- Determined by the XFEL schedule first RF system components must be delivered early 2009 for the various component test facilities.

- The components for the XFEL injector must be received only shortly after. However delivery of the major amount of all components is planned for 2010 to 2012. 